\title{
Antibiofilm and Anti-Quorum Sensing Activities of Vaginal Origin Probiotics
}

\author{
Esin Kiray ${ }^{1}$ \\ 'Kirsehir Ahi Evran University, Vocational School of Health Services, Kirsehir, Turkey
}

ORCID IDs of the author: E.K. 0000-0002-6908-5909

Please cite this article as: Kiray E. Antibiofilm and Anti-Quorum Sensing Activities of Vaginal Origin Probiotics. Eur J Biol 2021; 80(2): 82-90. DOI: 10.26650/EurJBiol.2021.932640

\section{ABSTRACT}

Objective: Multidrug-resistant bacteria generally use cell-to-cell communication that leads to biofilm formation as a resistance development mechanism. Some pathogenic bacteria can form biofilms through a mechanism called Quorum sensing (QS). QS inhibition is one of the effective approaches to prevent biofilm formation.

Materials and Methods: 20 Lactic acid bacteria (LAB) previously associated with identification by $16 \mathrm{~S}$ rRNA sequence analysis were used. Antibiofilm activities of metabolites of strains related to microplate based Antibiofilm method on Staphylococcus aureus ATCC 29213, Escherichia coli ATCC 25922, Pseudomonas aeruginosa ATCC 27853. Chromobacterium violaceum ATCC 12472 was used as an indicator in the anti-QS activities of LAB. The study was also performed by ELISA test on the immunomodulatory effect of LAB human peripheral blood mononuclear cells.

Results: All of the metabolites tested showed statistically significant antibiofilm activity on biofilms of pathogenic microorganisms. Although there was a difference between metabolites, Lactobacullus paracasei L2 and L20 strains had a high inhibitory effect on S. aureus (95.1\%) and P. aeruginosa by $92.7 \%$, respectively. L. plantarum L8 strain had $95.7 \%$ antibiofilm activity on E. coli. It was also determined that LAB has anti-QS activities in different concentrations. The immunomodulatory effect of LAB was found to produce higher IFN- $\gamma$ than the controls, whereas IL-10 concentrations were lower.

Conclusion: Bacteria use QS to regulate various sequences of functions, including virulence and biofilm formation. Therefore, using bacteria with strong probiotic properties as QS inhibitory agents seems to be a promising approach to reduce or suppress biofilm formation of pathogenic bacteria.

Keywords: Probiotics, Antibiofilm, Anti-quorum sensing, IFN - $\gamma$, IL-10

\section{INTRODUCTION}

Today, antibiotic resistance is spreading faster than ever. Resistance to the various antibacterial compounds used by bacteria to treat clinical infections and the spread of these resistant bacteria is a serious problem in society (1). Biofilm formation is one of the uses of bacteria to develop such resistance (2). Biofilms, microorganisms attach to living or non-living surfaces, allowing them to remain after polymeric substances they produce themselves. These structures act as a kind of shield for microorganisms. Microorganisms within the biofilm structure can be protected from effects such as cell response, antimicrobial treatment and adverse environmental conditions (3).

Biofilm-producing bacteria are more resistant to antibiotics, as the biofilm matrix will help prevent penetration of the antibiotic. Therefore, it is necessary to find microorganisms or compounds capable of inhibiting or destroying the biofilm in order to control the attack of the biofilm-forming pathogenic bacteria $(3,4)$.

Quorum sensing (QS) is a mechanism that can detect the population density of microorganisms and control gene expression after this density reaches a certain rate (4). 
Some pathogenic bacteria create biofilms using a mechanism called QS. QS is a form of communication between bacteria by various extracellular signaling molecules called autoinductors. Bacteria regulate the expression of virulence factors, production of secondary metabolite products, biofilm formation and communication between the host and other microorganisms through these signal molecules (5). During QS, signal molecules released from bacteria bind to other bacterial receptors and genes that enable communication within and between species are transcribed (6). In addition, virulence factors are also effective in cellular processes such as disinfectant tolerance, spore formation, toxin production, and regulation of mobility $(4,7)$. QS inhibition (QSI) is seen as an effective way of controlling bacterial infections, since pathogenic microorganisms prevent biofilm formation and reduce bacterial virulence (8).

Some recent studies show that the QS mechanism may be associated with bacterial resistance (9). Therefore, inhibition of the QS mechanism is a promising new antibacterial strategy that can not only inhibit the development of bacterial resistance, but also the expression of virulence genes associated with population density (4).

Lactic acid bacteria (LAB) are found in the mouth, vagina and intestines as a normal flora member in humans (5). The metabolites such as lactic acid, acetic acid, hydrogen peroxide and bacteriocin act as a protective agent in these areas thanks to their antagonism effects (10). The number of studies reporting the positive effects of flora member microorganisms such as LAB on the organism has increased and whether they can be used as an alternative in the treatment of diseases (11). It is seen as one of the powerful options (5).

The purpose of this study is to determine the anti-QS activity of $L A B$ with probiotic characters isolated from the vaginal flora using Chromobacterium violaceum as an indicator bacteria and to investigate the antibiofilm activity of these bacteria against biofilm-forming bacteria and determine their immunomodulatory effect.

\section{MATERIALS AND METHODS}

\section{Bacteria Used in the Experiment}

In our study, LAB isolated from vaginal swab samples of healthy women who previously applied to the Kırşehir Ahi Evran University Training and Research Hospital, Department of Obstetrics and Gynecology were used. The strains identified by $16 \mathrm{~S}$ rRNA sequence analysis were five Lactobacillus plantarum, four Lactobacillus paracasei and Lactobacillus rhamnosus, three Pediococcus acidilactici and one Lactobacillus gasseri, Lactobacillus crispatus, Lactobacillus acidophilus and Lactobacillus acidophilus. A total of 20 LAB were used $(10,12)$.

\section{Bacterial Culture Conditions}

The De Man Rogosa Sharpe (MRS) solid and liquid Broth (Merck, Germany) ( $\mathrm{pH}$ 6.5) medium was used in the development and activation of LAB. The strains were incubated for 24-48 hours at $37^{\circ} \mathrm{C}$ in the MRS medium under anaerobic conditions (10).
The pathogenic bacteria used in the study were Staphylococcus aureus ATCC 29213, Escherichia coli ATCC 25922, Pseudomonas aeruginosa ATCC 27853, Enterobacter aerogenes ATCC 13048, Bacillus cereus CU1065, Enterococcus faecalis ATCC 29212 and Bacillus subtilis (W168). Pathogen bacteria were activated in a Tryptic Soy Broth (TSB) medium under aerobic conditions at $37^{\circ} \mathrm{C}$ for 18 hours.

\section{Investigation of Anti-Quorum Activities of LAB}

The monitor strain C. violaceum ATCC 12472.was grown in 50 $\mathrm{mL}$ of the TSB medium and then incubated in an orbital shaker (120 rpm) at $28^{\circ} \mathrm{C}$ for 48 hours. LAB was streaked on TSA in a straight line and left overnight to develop. Then, $100 \mu \mathrm{L}$ of the monitor strain (OD $600=0.132$ ) were placed in $2 \mathrm{~mL}$ of semi-solid agar $(0.75 \%$ agar) for plating on pre-streaked LABs. After incubation, a positive result was observed with the inhibition of violacein pigmentation (opaque region) around the line of $L A B$ isolates of $C$. violaceum (13).

\section{Extraction of QS Inhibitory Substances}

Strains showing anti-QS activity were extracted using the liquid-liquid extraction method (14). Bacterial cultures were grown in $100 \mathrm{~mL}$ of the MRS broth medium and then incubated at $28^{\circ} \mathrm{C}$ for 48 hours in an orbital shaker incubator (120 rpm) (Thermo Scientific MAXQ 4450). After the cultures were centrifuged at $10,000 \mathrm{~g}$ for 15 minutes, the supernatants were mixed in equal proportions with ethyl acetate. The solvent layer was allowed to evaporate in the rotary evaporator. An oven vacuum was used to obtain a pure crude extract. The crude extract was stored at $-20^{\circ} \mathrm{C}$ as a $20 \mathrm{mg} / \mathrm{mL}$ stock (w/v) (14). The obtained raw extracts were used in other studies to be carried out.

\section{Antibacterial Activity of Extracts}

Antibacterial activity of the crude extracts was carried out using the agar well diffusion method. Staphylococcus aureus ATCC 29213, E. coli ATCC 25922, P. aeruginosa ATCC 27853, E. aerogenes ATCC 13048, B. cereus CU1065, E. faecalis ATCC 29212 and B. subtilis (W168) were used as pathogenic microorganisms in the study. Pathogenic bacteria were developed on Brain Heart Infusion Agar (BHIA) (Merck, Germany). The extracts were then applied to the well with $100 \mu \mathrm{L}$ of solution at a concentration of 10 and $20 \mathrm{mg} / \mathrm{mL}$. Streptomycin $(10 \mathrm{mg} / \mathrm{mL})$ (Merck, Germany) was used as positive control and DMSO as negative control. Plates were incubated at $37^{\circ} \mathrm{C}$ for 24 hours. The study was repeated three times. Antimicrobial activity was evaluated by measuring the zone diameters in $\mathrm{mm}$ around the wells and taking the average of three runs (15).

\section{Detection of Anti-QS Activity}

Anti-QS activity of crude extracts against $C$. violaceum was evaluated by agar well diffusion method. After C. violaceum was spread on TSA with a sterile drigalski spatula, $6 \mathrm{~mm}$ diameter cavities were made on the plates. Then, the extract was applied to the wells at a concentration of 10 and $20 \mathrm{mg} / \mathrm{mL}(50 \mu \mathrm{L})$. In this test, DMSO was used as a negative control and Streptomycin $(10 \mathrm{mg} / \mathrm{mL})$ was used as a positive control. The plates were incubated at $28^{\circ} \mathrm{C}$ for 24 hours. Anti-QS activity was observed 
through a turbid halo zone against a background of violacein pigment. The study was repeated three times (13).

\section{Antibiofilm Activity of Extracted QSI}

After pathogenic bacteria were developed in BHIA, for antibiofilm testing, equal proportions of crude extract and bacterial cultures (OD $600=0.132$ ) were transferred to 96 -well microtiter plates (polystyrene) and incubated for 24 hours at $37^{\circ} \mathrm{C}$. Sterile MRS broth $(100 \mu \mathrm{l})$ was used as negative control. The adhered cells were washed twice, then allowed to air dry. Staining was carried out without being aseptic. Biofilms were stained with $200 \mu \mathrm{L} 0.4 \%(\mathrm{w} / \mathrm{v})$ crystal violet solution for 30 minutes. After rinsing the wells twice with water, they were allowed to dry with air again. Ethanol was used as solvent. Optical density was measured at $595 \mathrm{~nm}$. BHIB was used as blank and bacterial cultures without extracts were used as controls. Percent biofilm inhibition was calculated by the formula below (3). The study was repeated three times.

Percentage biofilm inhibition $=\frac{(\text { Control OD595) }- \text { Treated OD595) }}{(\text { Control OD595) }} \times 100 \%$

\section{Quantitative Determination of the Amount of QS}

In the quantitative determination of $\mathrm{QS}$ production by $\mathrm{C}$. violaceum in the presence of $L A B$, made small changes in the method and was measured by photometrically (16). Briefly, LAB activated in MRS medium was transferred to tubes with $2 \mathrm{ml} \mathrm{TSB}$ medium and serial dilutions were made $(0.5-0.062 \mathrm{mg} / \mathrm{ml}) . C$. violaceum was incubated at $28^{\circ} \mathrm{C}$ until complete pigmentation was achieved in TSA medium. $100 \mu \mathrm{l}$ of $C$. violaceum was added to each dilution and incubated for 1 night. The next day, $50 \mu \mathrm{l}$ of $10 \%$ Sodium dodecyl sulfate (SDS) were added onto the cultures transferred to eppendorf tubes $(200 \mu \mathrm{l})$ and lysed by vortexing for 5 seconds and incubating for 5 minutes at room temperature. Next, $900 \mu \mathrm{l}$ of butanol were added and centrifuged at 13,000 . The absorbance of the supernatant at $585 \mathrm{~nm}$ was measured (Spectronic 20D Hewlett Packard, Germany). Percent inhibition results were determined as [(Control OD - processed OD) / control OD] x 100 (16).

\section{Immunomodulatory Effect of LAB}

Isolation of human peripheral blood mononuclear cells (hPBMCs) from healthy volunteers and treatment of $L A B$ was performed as previously described. Human PBMCs $\left(2 \times 10^{5}\right.$ cells / well) were seeded in 96-well tissue culture plates and treated with $2 \times 10^{6}$ colony forming $\mathrm{LAB}$ (hPBMCs/LAB ratio: $1 / 10$ ) at $37^{\circ} \mathrm{C}$ and $5 \% \mathrm{CO}_{2}$ for 48 hours. Use of phytohemagglutinin ( 2 $\left.\mu \mathrm{g} \mathrm{ml}^{-1}\right)$, E. coli lipopolysaccharide $\left(1 \mathrm{\mu g} \mathrm{ml}^{-1}\right)$ or as medium control experiments only interferon-gamma (IFN- $\gamma$ ) and interleukin-10 (IL-10) concentrations were determined depending on the enzyme according to the manufacturer's instructions (17). The protocol was approved by the Kırıkkale University Faculty of Medicine Ethics Committee.

\section{Statistical Data Analysis}

Statistical data analysis was performed using the SPSS program (Ver23, Chicago, IL, USA). All data are given as mean \pm standard error. Student's t-test method was used for comparison of con- trol and test groups. Differences between groups with a p-value of $<0.05$ were considered significant.

\section{RESULTS}

\section{Anti-QS Activities of LAB}

All 20 LAB isolated in previous studies showed different levels of an anti-quorum sensing activity. Inhibition zone diameters of some LAB are given in Figure 1. Especially, L6, L7, L9, L12 and L19 strains were found to have strong anti-quarum sensing activity.
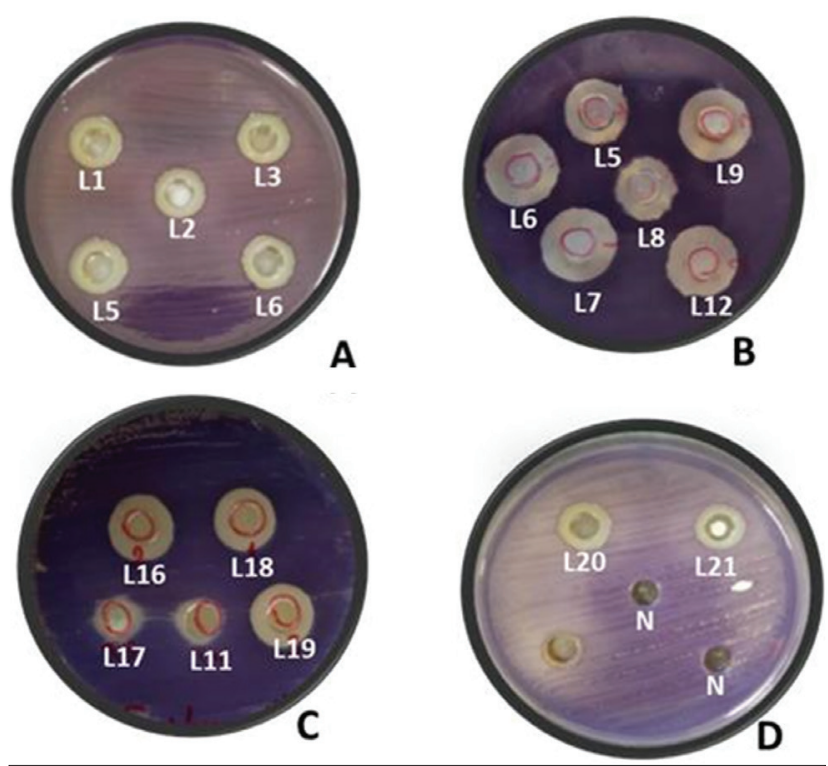

Figure 1 . The inhibition zone activity of vaginal $L A B$ bacteria $(A, B, C$ and $D)$ used in the present study.

\section{Antibacterial Activity of Extracts}

Antibacterial test was carried out in order to prevent false positive results that may be encountered in antibiofilm test. It has been observed that the crude extracts of 20 LAB produced by using the well diffusion method have a strong antibacterial effect on pathogenic microorganisms. Antibacterial activity was evaluated by measuring the zone diameters in $\mathrm{mm}$ around the wells and taking the average of three runs (Table 1). It was found that in addition to the strains with high anti-QS activity, the L5 and L13 strains also showed strong antibacterial activity.

\section{Detection of anti-QS activity}

Individual $L A B$ isolates were found to have their own optimal concentrations, but most of them did not show activity at a concentration of $10 \mathrm{mg} / \mathrm{mL}$ or showed lower activity, especially better activity at a concentration of $20 \mathrm{mg} / \mathrm{mL}$. It was observed that the Lactobacillus L16 strain formed the highest zone diameter at a concentration of $20 \mathrm{mg} / \mathrm{mL}$. The anti-QS activity results of $L A B$ are given in Table 1 .

\section{Antibiofilm Activity of Extracted QSI}

It has been observed that LAB raw extracts have a different inhibitory activity against all pathogenic microorganisms used in 
Table 1. Detection of anti-quarum sensing (QS) activity of crude extracts ( $\mathrm{mg} / \mathrm{mL}$ ) and antibacterial activity on pathogenic microorganisms (mm).

\begin{tabular}{|c|c|c|c|c|c|c|c|c|c|}
\hline \multirow{2}{*}{ Lactic Acid Bacteria } & \multicolumn{2}{|c|}{$\begin{array}{l}\text { Diameter of } \\
\text { pigment inhibition } \\
(\mathrm{mg} / \mathrm{mL})^{*}\end{array}$} & \multicolumn{7}{|c|}{ Antibacterial activity on pathogenic bacteria $(\mathrm{mm}) * *$} \\
\hline & 10 & 20 & $\begin{array}{l}\text { E. coli } \\
\text { ATCC } \\
25922\end{array}$ & $\begin{array}{l}\text { S. aureus } \\
\text { ATCC } \\
29213\end{array}$ & $\begin{array}{l}\text { P. aer. } \\
\text { ATCC } \\
27853\end{array}$ & $\begin{array}{l}\text { E. aer. } \\
\text { ATCC } \\
13048\end{array}$ & $\begin{array}{l}\text { B. cereus } \\
\text { ATCC } \\
6633\end{array}$ & $\begin{array}{l}\text { B. subtilis } \\
\text { (W168) }\end{array}$ & $\begin{array}{l}\text { E. faecalis } \\
\text { ATCC } \\
29212\end{array}$ \\
\hline Lactobacillus paracasei L1 & - & 14 & - & - & 14 & 13 & 18 & 10 & 18 \\
\hline Lactobacillus paracasei L2 & - & 13 & - & - & 12 & 15 & 18 & 11 & 18 \\
\hline Lactobacillus paracasei L3 & - & 14 & - & - & 16 & 12 & 16 & - & 16 \\
\hline Lactobacillus crispatus L5 & 10 & 15 & 14 & - & 13 & 14 & 22 & 12 & 17 \\
\hline Pediococcus acidilactici L6 & 9 & 15 & 15 & 14 & 20 & 21 & 20 & - & 14 \\
\hline Pediococcus acidilacitici L7 & 10 & 19 & - & - & 11 & 15 & 18 & - & - \\
\hline Lactobacillus rhamnosus L8 & - & 15 & - & 13 & 10 & - & 17 & 11 & 12 \\
\hline Lactobacillus plantarum L9 & 10 & 18 & 14 & - & 16 & 18 & 16 & - & 19 \\
\hline Lactobacillus gassei L10 & 10 & 13 & 12 & - & - & 14 & 16 & - & 14 \\
\hline Pediococcus acidilactici L11 & - & 11 & - & - & - & - & 16 & - & - \\
\hline Lactobacillus rhamnosus L12 & - & 19 & 17 & - & - & - & 15 & 12 & 15 \\
\hline Lactobacillus rhamnosus L13 & 10 & 18 & 20 & - & 17 & 18 & 16 & 12 & 19 \\
\hline Lactobacillus acidophilus L14 & 12 & 19 & 17 & - & - & - & - & - & 12 \\
\hline Lactobacillus rhamnosus L15 & 11 & 13 & 17 & 14 & - & 14 & 14 & 13 & 14 \\
\hline Lactobacillus plantarum L16 & 13 & 17 & 23 & - & 14 & 16 & 15 & 14 & - \\
\hline Lactobacillus spp. L17 & - & 11 & 20 & - & - & 18 & 17 & 12 & 15 \\
\hline Lactobacillus plantarum L18 & 12 & 16 & 14 & - & - & - & - & 12 & 18 \\
\hline Lactobacillus plantarum L19 & 10 & 16 & 17 & 15 & - & 18 & - & 19 & 20 \\
\hline Lactobacillus paracasei L20 & 9 & 14 & 20 & - & - & 15 & - & 15 & 16 \\
\hline Lactobacillus plantarum L21 & 8 & 14 & - & - & - & 17 & - & 12 & 14 \\
\hline $\begin{array}{l}{ }^{*} \text { It was studied in the antibacterial act } \\
{ }^{* *} \mathrm{Q} \text { inhibition (radius of pigment inh } \\
<3 \mathrm{~mm} \text { ); weak active (3-11mm); mode } \\
\text { E. aer: Enterobacter aerogenes }\end{array}$ & $\begin{array}{l}\text { y study at } \\
\text { ion in } \mathrm{mm} \\
\text { active }(1\end{array}$ & $\begin{array}{l}\text { rations of } \\
\text { us of grow } \\
\text { n); strong }\end{array}$ & $\begin{array}{l}\text { and } 20 \mathrm{~m} \\
\text { and pigm } \\
\text { tive }(>15 \mathrm{~m}\end{array}$ & $\begin{array}{l}/ \mathrm{mL} \text {. } \\
\text { nt inhibition - } \\
\text { n). Abbrevation }\end{array}$ & $\begin{array}{l}\text { radius of b } \\
\text { s: CFU: Col }\end{array}$ & $\begin{array}{l}\text { cterial grow } \\
\text { ny Forming }\end{array}$ & $\begin{array}{l}\text { th inhibition. } \\
\text { Unit, P. aer: Ps }\end{array}$ & $\begin{array}{l}\text { Not active (-, in } \\
\text { eudomonas aer }\end{array}$ & $\begin{array}{l}\text { hibition zone } \\
\text { uginosa, }\end{array}$ \\
\hline
\end{tabular}

the study. As indicated in Figure 2, it was determined that the best biofilm inhibition was in the S. aureus ATCC 29213 and E. coli ATCC 25922 strains, and the least inhibition activity was on P. aeruginosa ATCC 27853.

While the strain showing good inhibitory effect on S. aureus was the Lactobacullus L2 strain (95.1\%), the strain showing the best effect on E. coli (95.7\%) was the L8 strain. While most of the test strains showed low activity on P. aeruginosa, only the L20 strain was found to have a high inhibitory effect of $92.7 \%$ (Figure 2).

\section{Quantitative Determination of the Amount of QS}

The production of violacein was quantitatively determined by C. violaceum in the presence of the $L A B$ extract. The effect of $\mathrm{LAB}$ on violet pigment in different concentrations extract $(0.5$ $0.062 \mathrm{mg} / \mathrm{ml}$ ) is given in Figure 3.

\section{Immunomodulatory Effect of LAB}

Culture supernatants of LAB were incubated with hPBMCs isolated from healthy volunteers for 48 hours. Production levels of immunostimulating IFN- $\gamma$ and immunoregulatory cytokines 


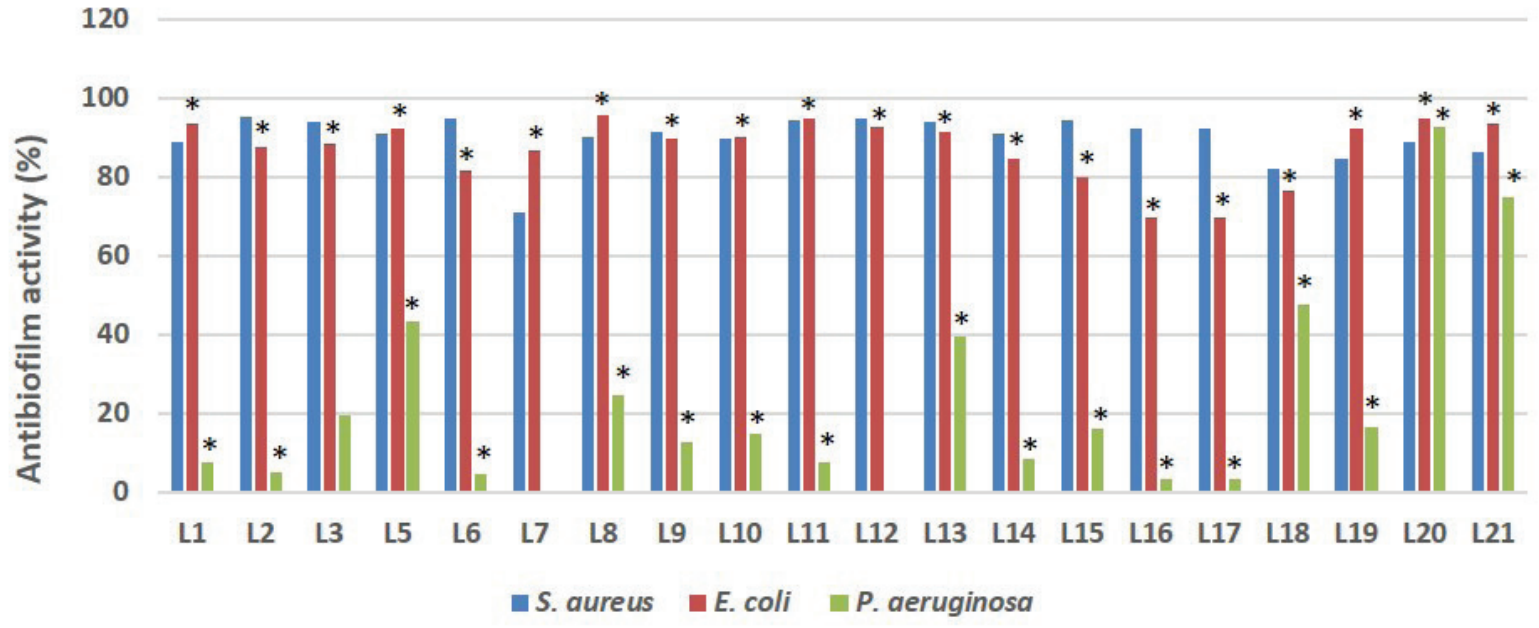

Figure 2. Antibiofilm activity of extracted QSI $(20 \mathrm{mg} / \mathrm{mL})$ against pathogenic bacteria. ${ }^{*} \mathrm{p}<0.05$ vs control.

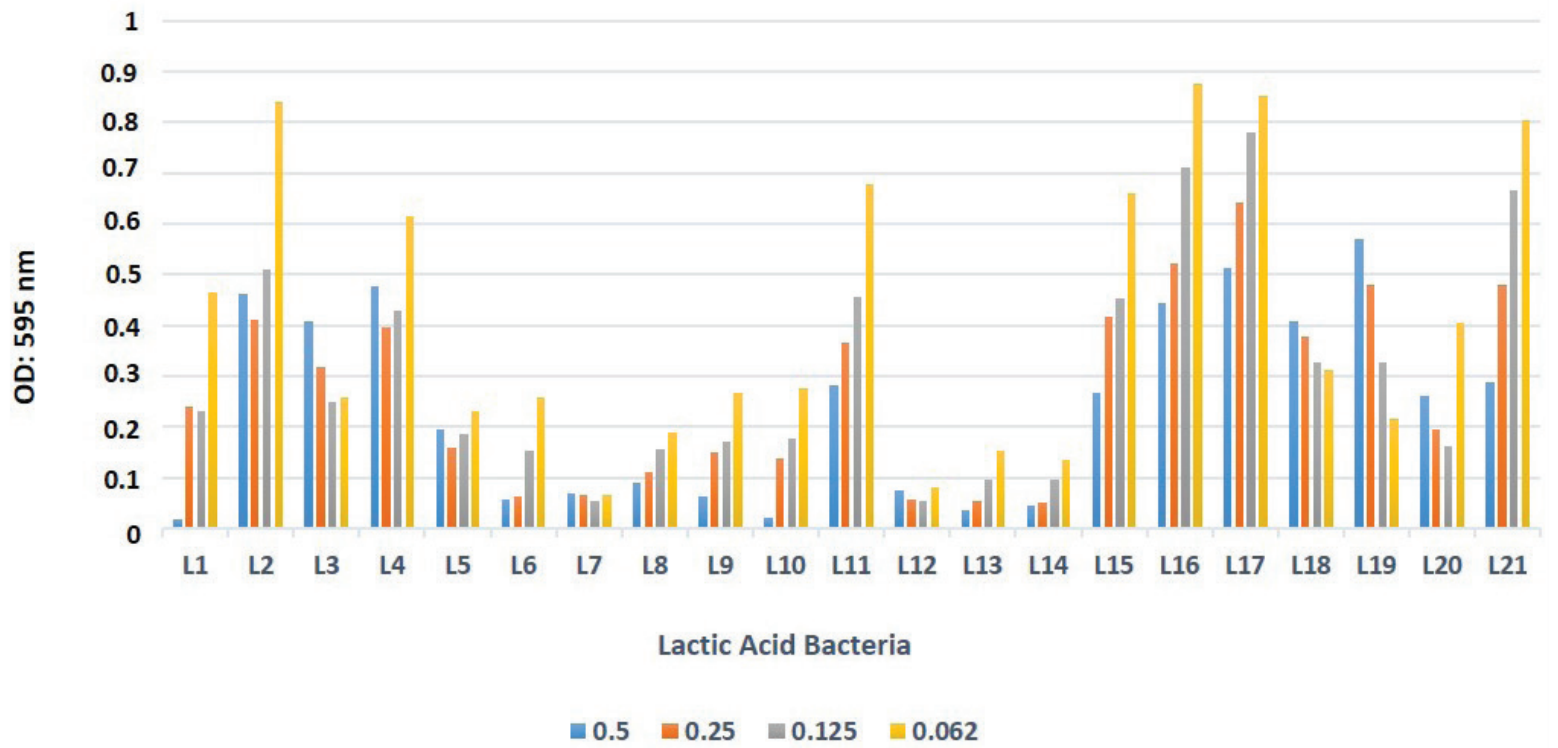

Figure 3. Effect of LAB extracts on violacein production. Different concentration of probiotic extract $(0.5-0.062 \mathrm{mg} / \mathrm{mL}) \mathrm{was}$ used to quantify the inhibition of violacein, an indicator of QS activity.

were measured by ELISA. While all LAB strains were found to produce higher IFN- $\gamma$ than the controls, the IL-10 concentrations were found to be lower (Table 2). It suggests that LAB has the capacity to support innate responses while suppressing adaptive inflammatory responses (18).

\section{DISCUSSION}

Currently, approximately $65 \%$ of all bacterial infections have been associated with bacterial biofilms (19). Clinical management of infections is difficult, as biofilms can hardly be detected by routine diagnostic tests. Methicillin-resistant
Staphylococcus aureus (MRSA), P. aeruginosa, S. epidermidis and Gardnerella vaginalis are the most common biofilm-forming microorganisms in the clinic. Due to the difficulties of these therapeutic agents of high clinical importance, there is a demand for new strategies. Today, antibiotic therapy is insufficient to fight biofilm-related infections; however, understanding the nature of biofilms will help us combat biofilm infections (5).

There is a need for new strategies to combat pathogenic microorganisms that have high clinical importance and cause high morbidity and mortality. Treatment with antibiotics is inadequate with biofilm-associated infections. Therefore, under- 
Table 2. Effect of filtered LAB supernatant on interferon- $\gamma$ (IFN- - ) production and interleukin-10 (IL-10) production in human peripheral blood mononuclear cells using enzyme-linked immunosorbent assay (ELISA)

\begin{tabular}{|c|c|c|c|c|c|}
\hline \multicolumn{6}{|c|}{ Cytokine concentration (pg/ml)* } \\
\hline Sample & IFN- $\gamma$ Mean $\pm S D^{a}$ & IL-10 Mean \pm SD & Sample & IFN-ץ Mean \pm SD & IL-10 Mean \pm SD \\
\hline Control & $17 \pm 1.0$ & $81 \pm 1.0$ & Control & $17 \pm 1.0$ & $81 \pm 1.0$ \\
\hline $\mathbf{L 1}$ & $43 \pm 0.5$ & $61 \pm 0.4$ & L12 & $56 \pm 0.4^{*}$ & $54 \pm 0.5$ \\
\hline L2 & $36 \pm 0.4$ & $52 \pm 0.2$ & L13 & $28 \pm 0.3$ & $45 \pm 0.4$ \\
\hline $\mathbf{L 3}$ & $56 \pm 0.5^{*}$ & $36 \pm 0.3^{*}$ & L14 & $38 \pm 0.1$ & $57 \pm 0.4$ \\
\hline $\mathbf{L 5}$ & $45 \pm 0.3$ & $45 \pm 0.5$ & $\mathbf{L 1 5}$ & $46 \pm 0.3$ & $62 \pm 0.2$ \\
\hline L6 & $21 \pm 0.1$ & $41 \pm 0.4$ & L16 & $49 \pm 0.2$ & $48 \pm 0.1$ \\
\hline L7 & $37 \pm 0.5$ & $35 \pm 0.1^{*}$ & L17 & $39 \pm 0.2$ & $56 \pm 0.4$ \\
\hline L8 & $45 \pm 0.4$ & $54 \pm 0.2$ & L18 & $51 \pm 0.4$ & $53 \pm 0.5$ \\
\hline L9 & $52 \pm 0.6$ & $58 \pm 0.5$ & L19 & $47 \pm 0.3$ & $38 \pm 0.6$ \\
\hline L10 & $38 \pm 0.4$ & $46 \pm 0.4$ & L20 & $44 \pm 0.6$ & $27 \pm 0.3^{*}$ \\
\hline L11 & $46 \pm 0.3$ & $51 \pm 0.5$ & L21 & $52 \pm 0.1$ & $45 \pm 0.4$ \\
\hline \multicolumn{6}{|c|}{$\begin{array}{l}\text { *It is seen that the supernatants of the } L 3 \text { and } L 12 \text { strains indicated with arrows in the table produced higher IFN- } \gamma \text { than the control, and the } L 3, L 7 \text { and } L 20 \text { strains } \\
\text { had higher inhibition rates of IL- } 10 \text { production compared to the control. } \\
\text { *All results showed significant difference from control }(p<0.05) \text {. } \\
\text { a SD: Standard deviation }\end{array}$} \\
\hline
\end{tabular}

standing the mechanism of biofilms and preventing the formation of biofilms has the potential to be a savior in combating these bacteria (5).

When bacteria species that communicate through signal molecules reach a certain density, they initiate gene expression that enables the synthesis of virulence factors. Therefore, blocking the communication between bacteria constitutes one of the new targets that can be achieved in antimicrobial therapy (20). Targeting the QS mechanisms, controlling bacterial virulence and the destruction of the infection by the host immune system is a striking strategy. Compounds with QSI effect are also new generation antimicrobial agents (21). Recent studies show that probiotics are one of the strongest options in combating pathogenic biofilms $(22,23)$.

Probiotics are live bacteria that, when administered adequately, have a positive effect on host health. Many in vivo and in vitro studies and genomic analyses such as transcriptomics have proven that probiotics can modify the host's mucosal and systemic immune response and protect the host against pathogenic microorganisms through various mechanisms $(10,24)$. In addition, bacteriocins produced by probiotics, hydrogen peroxide and various organic acids show antimicrobial effects against gastrointestinal pathogens (12). Because of these effects on pathogenic microorganisms, probiotics are thought to have the capacity to inhibit the formation of pathogens and biofilms.
The findings show that probiotics open a new horizon in the fight against biofilms. Probiotics do not exert a strong selective pressure on resistant microorganisms compared to conventional antibiotics used in clinical microbiology. Therefore, since probiotics are less cytotoxic than anti-QS agents and have a natural effect, they can be considered as the ideal choice in combating biofilm forms of pathogens (5).

In our study, using in vitro studies, we determined that various $\mathrm{LAB}$ species isolated from vaginal swabs of healthy women showed a strong antibiofilm activity, especially on S. aureus and E. coli strains, and also had anti-QS activity by using C. violaceum as an indicator bacterium.

Studies have shown a biofilm inhibition of $41.7 \%$ on $P$. aeruginosa of exopolysaccharide and bacteriocins obtained from various probiotics (11). It showed broad inhibition and antibiofilm effects against $P$. aeruginosa strains of the probiotic the $L$. fermentum strain isolated from local dairy products (25). It has been observed that the bacteriocin produced by Pediococcus acidilactici HW01 (HW01 bacteriocin) inhibits the biofilm formation of $P$. aeruginosa at a dose of $2 \mathrm{mg} / \mathrm{mL}$ by $66.41 \%(26)$.

The mechanism by which probiotics inhibit biofilm formation is not yet clear. Some in vitro studies show that probiotics can affect the expression of genes involved in QS, cell adhesion, virulence factors and biofilm formation $(27,28)$. 
Some probiotics have effects that inhibit the physiological behavior of bacteria due to QS. In a study, it was found that the production of lactic acid, short chain N-Acyl homoserine lactones (AHL) produced by probiotics, has an inhibitory effect on QS by suppressing the biofilm formation of $P$. aeruginosa (29). Again, L. helveticus, L. lactis, and L. casei strains showed similar inhibitory effects on $E$. coli O157: H7, Salmonella typhimurium and L. monocytogenes pathogens (30).

Organic acids synthesized by probiotics can act as QS antagonists, which can inhibit AHL production at the gene expression level and stop biofilm formation (5). In studies conducted in this direction, it was stated that the L. brevis strain, which has a strong probiotic property, has the potential to regulate the QS system (31).

Onbas et al. (20) investigated various effects of the probiotic L. plantarum F-10 strain isolated from the fecal microbiota of a healthy breastfed baby on P. aeruginosa ATCC 27853, methicillin-resistant S. aureus ATCC 43300 bacteria. In the study, L. plantarum F-10 was found to have antimicrobial, antibiofilm, anti-QS and antioxidant activity (20). Similarly, in our study, it was determined that the strong probiotic LAB isolated from the vaginal swabs of healthy women showed strong antibiofilm properties especially on S. aureus ATCC 29213 and E. coli ATCC 25922 strains.

Similar to our study, the antibiofilm effect of bio surfactants isolated from L. casei on S. aureus strains (32), in another study, the biosurfactants isolated from $P$. acidilactici and L. plantarum were also tested against $S$. aureus. Its antimicrobial, anti-QS and antibiofilm potential has been proven (33). In another study, it was reported that, L. reuteri (ATCC 23272), L. casei (ATCC 393), L. salivarius (ATCC 11741), and L. plantarum (ATCC 14917) strains inhibited biofilm formation and expression of QS-related Streptococcus mutans genes. The highest effect on S. mutans was detected in the L. casei and L. reuteri strains (27).

While it was determined that the supernatants of various LAB (L. lactis, L. rhamnosus and L. fermentum) showed biofilm and anti-QS activity against $P$. aeruginosa (34). The strains used in our study were found to have less antibiofilm and anti-quorum sensing activity on $P$. aeruginosa. Unlike other studies, our study includes various types of LAB together. In our study, it was determined that strains with strong antibiofilm properties showed anti-QS activity. The antibiofilm and anti-QS properties, cytokine profiles and IL-10 production capacities of the strains with proven probiotic importance are presented in comparison.

All the L. plantarum strains investigated in our study were found to have anti-QS activity. In a study, it was shown that the L. plantarum WCFS1 strain also showed high anti-QS activity similar to our study, and this microorganism also had a peptide-based QS-TCS (two components regulatory system). This has been reported as the reason why this species is more common in the environment and its adaptability is better than other species (35).
Microorganisms with probiotic properties as well as signaling molecules of pathogens low molecular weight have also been reported to produce bioactive compounds. These bioactive components are short-chain fatty acids, bacteriocin-like compounds, organic acids, hydrogen peroxide, nitric oxide and signaling molecules. These molecules toxins created by pathogens, harmful inactivates metabolites and signaling molecules by making or suppressing their production. They have been reported to inhibit the activity of pathogens (36).

In a study conducted in this context, it was shown that the $L$. acidophilus LA-5 strain showed strong anti-QS activity and protein-like molecules produced by this strain reduced enteropathogenic gene transcription, which is effective in the QS mechanism in inhibiting enterohemorrhagic E. coli O157:H7 (37). Similar results of a single strain of the L. acidophilus L14 strain in our study on E. coli ATCC 25922 type strain are given in Table 1 and Figure 2.

IL-10 is a regulatory cytokine that is of great importance in increasing Treg cell function and preventing excessive inflammation by reducing inflammatory cytokine responses. The production of IL-10 by the Lactobacillus species is one of the mechanisms that reveal the beneficial effect of probiotic microorganisms on the immune system $(18,27)$.

The number of comparative analyses at species level is low in the studies. For this reason, the immunomodulatory effect of $\mathrm{LAB}$ on $\mathrm{hPBMC}$ cytokine profiles and proliferative response was compared in our study (Table 2). In our study, supernatants of all LAB strains inhibited IL-10 production, but further research is needed in this area. IFN- $\gamma$ is the most important macrophage stimulating cytokine. It is critical in natural and acquired immunity. It stimulates the active macrophages to kill the microorganisms that they phagocyte. It induced higher levels of IFN$\gamma$ at the site of infection of the tested $L A B$, which could elicit innate and potentially adaptive immune responses. In other studies, lactic acid produced by vaginal LAB has a suppressive effect on IFN- $\gamma$ production in human $\mathrm{T}$ and natural killer cells, and this production is an important factor that provides protection against bacterial vaginosis $(17,38)$.

\section{CONCLUSION}

In the last few decades, a rapid increase in the number of bacteria resistant to antibiotics has been observed. Accordingly, instead of directly killing pathogenic bacteria, treating and controlling bacterial infections by blocking the communication system between them is considered a promising new strategy in the fight against pathogens. The probiotic properties of these strategies, which can be an alternative to antibiotics, have been determined, and it has been proven by studies that they can be mediated by microorganisms that affect the immune system. In our study, it was determined that most of the LABs with previously proven probiotic properties showed strong antibiofilm and anti-QS activity. In the future, the feasibility of anti-QS therapy in the fight against various pathogenic microorganisms is considered. In these treatment methods that can be applied, 
the use of probiotic microorganisms is considered appropriate. However, more research, screening programs and testing protocols are needed to establish these treatment modalities. It is also hoped that this practice will not cause the growth of resistant bacteria and will not destroy beneficial bacterial communities in the host, and that QS inhibitors will be used in conjunction with existing antibiotics to increase their effectiveness.

Acknowledgments: We would like to thank the scientific research projects coordinator of Kirsehir Ahi Evran University for their financial contributions.

Informed Consent: Written consent was obtained from the participants.

Peer Review: Externally peer-reviewed.

Ethics Committee Approval: The decision of the ethics committee of the study was taken from Kirikkale University Ethics Committee with the decision no 25/02 on 27.10.2014.

Conflict of Interest: Author declared no conflict of interest.

Financial Disclosure: This research was supported by Kirsehir Ahi Evran University Scientific Research Projects Project No: PYO-FEN.4001.16.012.

\section{REFERENCES}

1. Abdula N, Macharia J, Motsoaledi A, Swaminathan S, Vijay Raghavan $\mathrm{K}$. National action for global gains in antimicrobial resistance. Lancet 2016; 387: 3-5.

2. Fuqua C, Greenberg EP. Self-perception in bacteria: quorum sensing with acylated homoserine lactones. Curr Opin Microbiol 1998; 2: 183-9.

3. Theodora NA, Dominika V, Waturangi DE. Screening and quantification of anti-quorum sensing and antibiofilm activities of phyllosphere bacteria against biofilm forming bacteria. BMC Res Notes 2019; 12(1): 732.

4. Zhao X, Yu Z, Ding T. Quorum-sensing regulation of antimicrobial resistance in bacteria. Microorganisms 2020; 8(3): 425.

5. Barzegari A, Kheyrolahzadeh K, Khatibi SMH, Sharifi S, Memar MY, Vahed SZ. The battle of probiotics and their derivatives against biofilms. Infect Drug Resist 2020; 13: 659-72.

6. Krzyżek P. Challenges and limitations of anti-quorum sensing therapies. Front Microbiol 2019; 31(10): 2473.

7. Hawver LA, Jung S A, Ng WL. Specificity and complexity in bacterial quorum-sensing systems. FEMS Microbiol Rev 2016; 40(5): 738-52.

8. Liu L, Wu R, Zhang J, Shang N, Li P. D-Ribose interferes with quorum sensing to inhibit biofilm formation of Lactobacillus paraplantarum L-ZS9. Front Microbiol 2017; 8: 1860.

9. Jiang Q, Chen J, Yang C, Yin Y, Yao K. Quorum Sensing: A prospective therapeutic target for bacterial diseases. Biomed Res Int 2019; 2015978.

10. Kiray E, Kariptas E, Dagli SS. Evaluation of vaginal lactobacilli with potential probiotic properties and biotherapeutic effects isolated from healthy Turkish women. Fresenius Environ Bull 2020; 29424052.

11. Sharma V, Harjai K, Shukla G. Effect of bacteriocin and exopolysaccharides isolated from probiotic on P. aeruginosa PAO1 biofilm. Folia Microbiol 2018; 63: 181-90.
12. Kiray E, Kariptas E, Azarkan SA. Evaluation of vaginal lactobacilli with potential probiotic properties and biotherapeutic effects isolated from healthy Turkish women. PSM Micro 2019; 4(3): 56-70.

13. Abudoleh SM, Mahasneh AM. Anti-quorum sensing activity of substances isolated from wild berry associated bacteria. Avicenna J Med Biotechnol 2017; 9(1): 23-30.

14. Younis KM, Usup G, Ahmad A. Secondary metabolites produced by marine streptomyces as antibiofilm and anti-quorum sensing inhibitor of uropathogen Proteus mirabilis. Environ Sci Pollut Res 2015; 23(5): 4756-67.

15. Tabbouche SA, Gurgen A, Yildiz S, Kilic AO, Sokmen M. Antimicrobial and antiquorum sensing activity of some wild mushrooms collected from Turkey. MSU J Sci 2017; 5(2): 453-7.

16. Han MSA, Zahin M, Hasan S, Husain FM, Ahmad I. Inhibition of quorum sensing regulated bacterial functionsby plant essential oils with special reference to clove oil. Lett Appl Microbiol 2009; 49(3): 354-60.

17. Vissers YM, Snel J, Zuurendonk PF, Smit BA, Wichers HJ, Savelkoul HFJ. Differential effects of Lactobacillus acidophilus and Lactobacillus plantarum strains on cytokine induction in human peripheral blood mononuclear cells. FEMS Immunol Med Microbiol 2010; 59(1): 60-70.

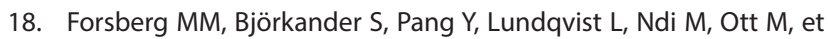
al. Extracellular membrane vesicles from lactobacilli dampen IFN- $\gamma$ responses in a monocyte-dependent Manner Sci Rep 2019; 9: 17109.

19. Jamal M, Ahmad W, Andleeb S, Jalil F, Imran M, Nawaz MA, et al. Bacterial biofilm and associated infections. JCMA 2018; 81(1): 7-11.

20. Onbas T, Osmanagaoglu O, Kiran F. Potential properties of Lactobacillus plantarum F-10 as a bio-control strategy for wound infections. Probiotics Antimicro 2019; 11(4): 1110-23.

21. Garcia-Contreras R, Nunez-Lopez L, Jasso-Chavez R. Quorum sensing enhancement of the stress response promotes resistance to quorum quenching and prevents social cheating. ISME J 2015; 9(1): 115-25.

22. Kim NN, Kim WJ, Kang SSJFC. Antibiofilm effect of crude bacteriocin derived from Lactobacillus brevis DF01 on Escherichia coli and Salmonella typhimurium. Food Control 2019; 98: 274-80.

23. Kaur S, Sharma P, Kalia N, Singh J, Kaur S. Antibiofilm properties of the fecal probiotic lactobacilli against vibrio spp. Front Cell Infect Microbiol 2018; 8: 120.

24. Iannitti T, Palmieri B. Therapeutical use of probiotic formulations in clinical practice. Clin Nutr 2010; 29(6): 701-25.

25. Shokri D, Khorasgani MR, Mohkam M, Fatemi SM, Ghasemi Y, Taheri-Kafrani A. The inhibition effect of lactobacilli against growth and biofilm formation of Pseudomonas aeruginosa. Probiotics Antimicrobe Proteins 2018; 10(1): 34-42.

26. Lee D, Kim BS, Kang SS. Bacteriocin of Pediococcus acidilactici HW01 inhibits biofilm formation and virulence factor production by Pseudomonas aeruginosa. Probiotics Antimicro 2020; 12(1): 73-81.

27. Wasfi R, Abd El-Rahman OA, Zafer MM, Ashour HM. Probiotic Lactobacillus sp. inhibit growth, biofilm formation and gene expression of caries-inducing Streptococcus mutans. J Cell Mol Med 2018; 22(3): 1972-83.

28. James KM, MacDonald KW, Chanyi RM, Cadieux PA, Burton JP. Inhibition of Candida albicans biofilm formation and modulation of gene expression by probiotic cells and supernatant. J Med Microbiol 2016; 65(4): 328-36.

29. Kiymaci ME, Altanlar N, Gumustas M, Ozkan SA, Akin A. Quorum sensing signals and related virulence inhibition of Pseudomonas aeruginosa by a potential probiotic strain's organic acid. Microb Pathog 2018; 121: 190-7. 
30. Gómez NC, Ramiro JM, Quecan BX, de Melo Franco BD. Use of potential probiotic lactic acid bacteria (LAB) biofilms for the control of Listeria monocytogenes, Salmonella typhimurium, and Escherichia coli O157: H7 biofilms formation. Front Microbiol 2016; 7: 863.

31. Qichuang Li, Yonglong Pan, Linxian Ding, Huachang Hong, Shuxia Yan, Binbin Wu, et al. draft genome sequence of Lactobacillus brevis Strain 3M004, a probiotic with potential quorum-sensing regulation. Genome Announc 2017; 5(36): e00675-17.

32. Merghni A, Dallel I, Noumi E. Antioxidant and antiproliferative potential of biosurfactants isolated from Lactobacillus casei and their antibiofilm effect in oral Staphylococcus aureus strains. Microb Pathog 2017; 104: 84-9.

33. Yan X, Gu S, Cui X. Antimicrobial, anti-adhesive and antibiofilm potential of biosurfactants isolated from Pediococcus acidilactici and Lactobacillus plantarum against Staphylococcus aureus CMCC26003. Microb Pathog 2019; 127: 12-20.

34. Rana S, Bhawal S, Kumari A, Kapila S, Kapila R. pH-dependent inhibition of $\mathrm{AHL}$-mediated quorum sensing by cell-free supernatant of lactic acid bacteria in Pseudomonas aeruginosa PAO1. Microb Pathog 2020; 28; 142: 104105.
35. Sturme MHJ, Francke C, Siezen RJ, de Vos WM, Kleerebezem M. Making sense of quorum sensing in lactobacilli: a special focus on Lactobacillus plantarum WCFS1. Microbiology 2007; 153: 3939-47.

36. Yılmaz-Yıldıran H, Karahan AG, Başyiğit-Kılıç G. Quorum sensing mechanism in lactic acid bacteria. Turk J Hygiene Exper Bio 2015; 72(1): 79-90.

37. Tabasco R, de Palencia PF, Fontecha Peláez C, Requena T. Competition mechanisms of lactic acid bacteria and bifidobacteria: fermentative metabolism and colonization. LWT-Food Sci Technol 2014; 55: 680-4.

38. Aldunate M, Srbinovski D, Hearps AC, Latham CF, Ramsland PA, Gugasyan R, Cone RA, Tachedjian G. Antimicrobial and immune modulatory effects of lactic acid and short chain fatty acids produced by vaginal microbiota associated with eubiosis and bacterial vaginosis. Front Physiol 2015; 6: 164. 